FEATURE

Nicholas Palmer and Matthew Hughes

Office for National Statistics

\title{
Labour Force Survey: interim reweighting 2007
}

O n 14 November 2007, revised Labour Force Survey (LFS) estimates, that is, the aggregates in the Labour Market Statistics (LMS) First Release, were published to take into account the latest LFS population data. The LFS data sets used for detailed analysis, known as LFS microdata, are not affected. They continue to be weighted to the population estimates published in February 2003 . $^{1}$

On 22 August 2007, the Office for National Statistics (ONS) published the 2006 mid-year population estimates for the UK and revised estimates for 2002 to 2005. These were followed by the 2007 Q2 experimental quarterly population estimates for England and Wales on 13 September, which provided revised projections for mid2007. These new and revised estimates have been incorporated into the calculation of the population estimates that feed into the LFS aggregate results.

In previous years, the reweighting of the LFS aggregates has coincided with the implementation of the annual review of the seasonal adjustment of the LFS. A detailed review has not been carried out in 2007; there have therefore been no changes to the way the series are seasonally adjusted.

This article gives an overview of the population estimate revisions and their impact on the headline and regional LFS aggregate results.

\section{Background to the LFS}

The LFS is a continuous UK household sample survey, which collects information from approximately 52,000 households each quarter (around 120,000 people). Since those responses reflect only a sample (approximately 1 in 400) of the total population, they are weighted on the basis of subnational population totals by age and sex to give estimates for the entire household population. The population estimates used to produce the LFS population totals are based on the annual mid-year population estimates (MYEs), and latest projections based on these MYEs. These are updated on an annual cycle and thus the LFS estimates are revised on the same basis. These annual revisions have been in operation since a new system of interim reweighting of LFS data was introduced in 2002. This methodology ensures that the LFS time series continues to be kept closely in line with the latest population estimates, thus reflecting a more accurate picture of the UK labour market.

In order to remain consistent with the LFS sample, the population estimates are adjusted to exclude those outside the coverage of the LFS. Consequently, communal establishments, apart from people living in National Health Service accommodation and students living in halls of residence who have a UKresident parent, are excluded from the LFS household population estimates. A fuller description of the history of the LFS and its methodology can be found in the Labour Force Survey User Guide, Volume 1. ${ }^{2}$ 


\section{Figure 1}

\section{LFS population aged $16+$ totals, previous and new population estimates $^{1}$}

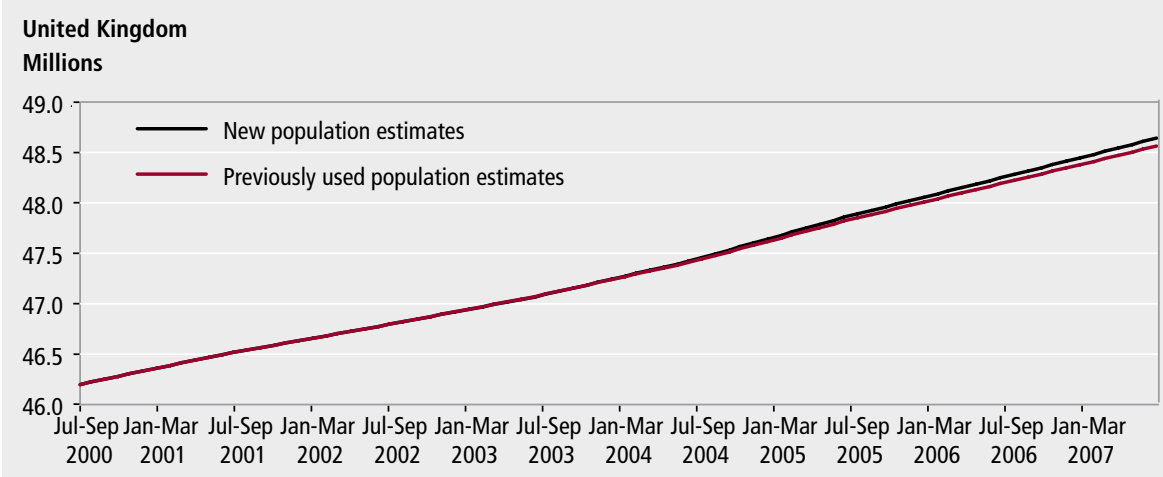

Note:

1 Rolling three-month periods, July to September 2000 to June to August 2007.

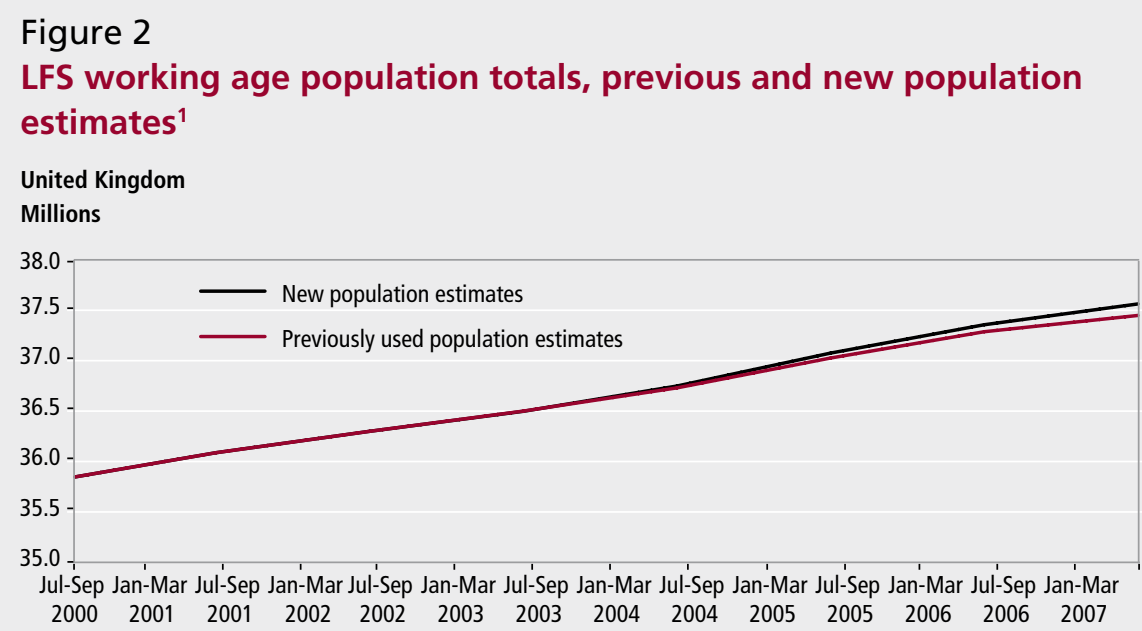

Note:

1 Rolling three-month periods, July to September 2000 to June to August 2007.

Table 1

Revisions to headline LFS results, June to August 2007

\begin{tabular}{lrrr}
\hline Status & Level & $\begin{array}{r}\text { Level as a } \\
\text { percentage }\end{array}$ & $\begin{array}{r}\text { Rate } \\
\text { (percentage points) }\end{array}$ \\
\hline Population aged 16+ & & & 0.1 \\
Economically active & 91,000 & 0.3 & 0.1 \\
In employment & 85,000 & 0.3 & - \\
Unemployed & 6,000 & 0.4 & -0.1 \\
Economically inactive & $-12,000$ & -0.1 & - \\
& & & - \\
Working age population & & & - \\
Economically active & 95,000 & 0.3 & - \\
In employment & 89,000 & 0.3 & 0.4 \\
Unemployed & 6,000 & 0.1 & - \\
Economically inactive & 20,000 & & \\
\hline
\end{tabular}

\section{LFS population estimates and reweighting the LFS}

The population estimates published in August and September 2007 indicate that the UK population was increasing at a slightly faster rate than had previously been estimated. Figure 1 and Figure 2 compare international migration, have contributed to the higher population growth shown in the latest LFS population aged $16+$ and working age estimates. Table A1 in the Appendix shows the revisions to the population aged $16+$ and working age at each mid-year point from 2002. The largest revisions were to the period prior to the month of the reweighting exercise, 0.2 per cent for the aged $16+$ estimates and 0.3 per cent for the working age estimates.

The impact of the population revisions is bigger on the working age population (Figure 2) than the aged $16+$ population (Figure 1). This is because the latest estimates for people over working age $(60+$ for females and $65+$ for males) are lower than those previously used. Table A2 shows the impact of the new population estimates on each age group.

\section{Revisions to LFS aggregates}

The remainder of this article will examine the impact of the population revisions on the headline indicators by labour market status. The largest revisions were to the period immediately before the month of the reweighting exercise - June to August 2007 - and these are summarised in Table 1.

For the population aged $16+$, the downward revision to the level of economically inactive people is mainly due to the downward revision to the number of people above working age. This is because economic inactivity is significantly more prevalent among people above working age than among those of working age.

Generally, since the population revisions are included in both the numerator and denominator for the rate calculations, the revisions to the rates are very small, no more than 0.1 of a percentage point and, in many cases, zero. Consequently the following analysis focuses on the levels rather than rates.

\section{LFS economically active estimates}

Figure 3 shows the impact of the population revisions on the LFS working age (16 to 59/64) economically active levels.

The UK working age economically active level has been increasing at a slightly higher rate over the period than had previously been estimated. The LFS working age economically active level combines the LFS working age employment and unemployment levels. These will be examined in more detail below. The largest revisions were to the period immediately before the month of the reweighting exercise, 0.3 per cent for the working age 


\section{Figure 3}

\section{LFS working age economically active totals, previous and new population estimates ${ }^{1}$}

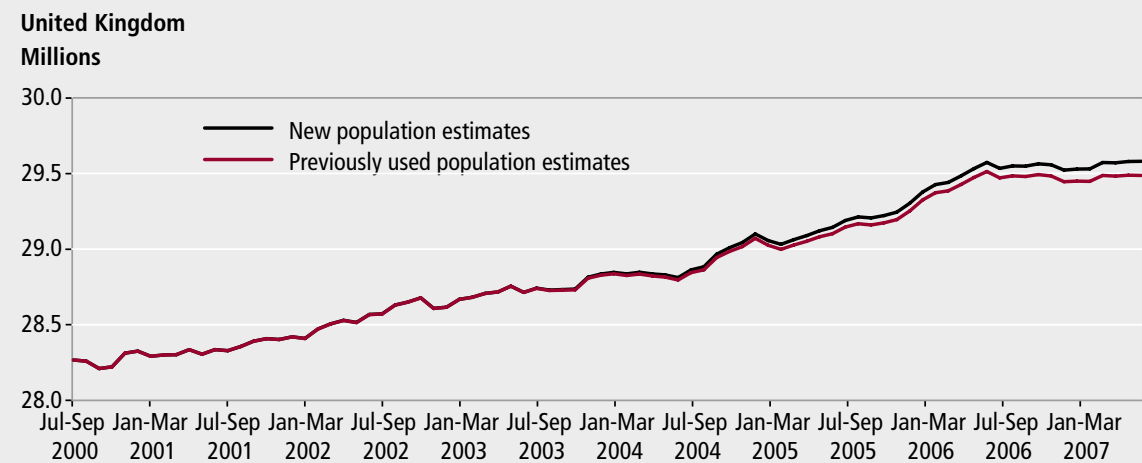

Note:

1 Rolling three-month periods, July to September 2000 to June to August 2007.

\section{Figure 4}

LFS working age economically inactive totals, previous and new population estimates ${ }^{1}$

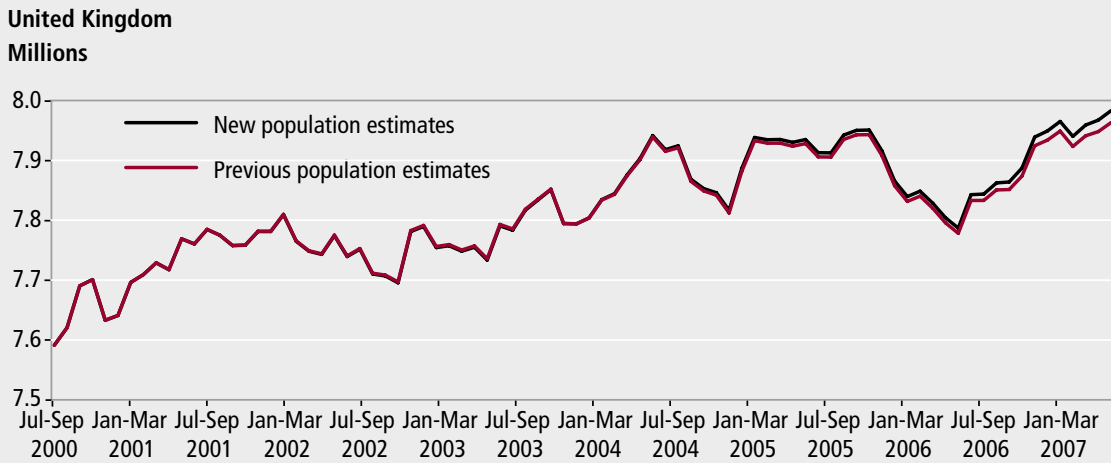

Note:

1 Rolling three-month periods, July to September 2000 to June to August 2007

\section{Figure 5}

LFS working age employment totals, previous and new population estimates $^{1}$

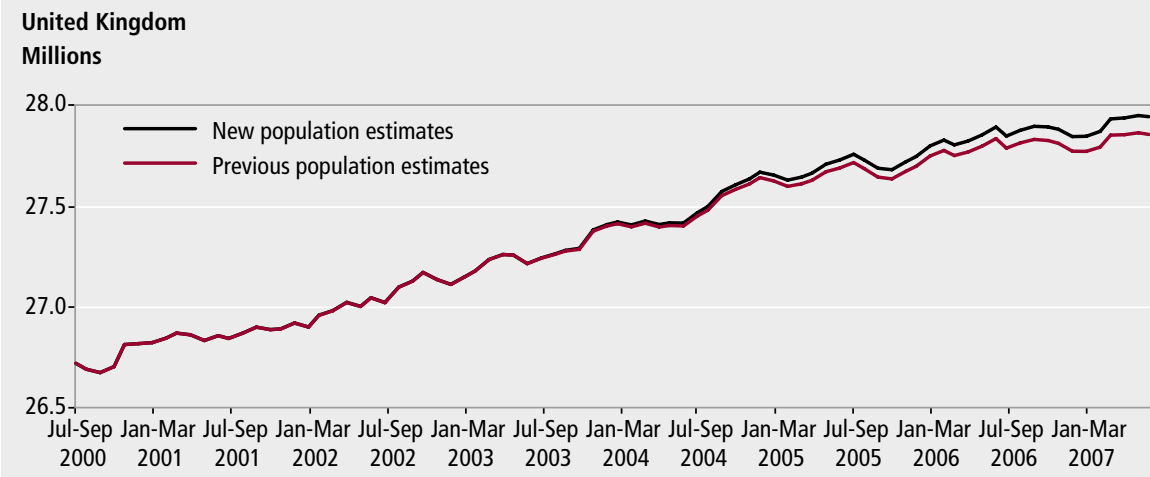

Note:

1 Rolling three-month periods, July to September 2000 to June to August 2007 economically active estimates.

\section{LFS economically inactive estimates}

Figure 4 shows the impact of the population revisions on the LFS working age (16 to 59/64) economically inactive levels.

The UK working age economically inactive level has been increasing at a slightly higher rate over the period than had previously been estimated. The revisions to the LFS working age economically inactive levels are no greater than 0.1 per cent, as seen for June to August 2007.

\section{LFS employment estimates}

Figure 5 shows the impact of the population revisions to the LFS working age (16 to 59/64) employment levels.

Table A3 shows the revisions to the employment levels for June to August 2007, broken down by age group. The largest revisions are to the period immediately before the reweighting, 0.3 per cent for the working age employment estimates.

\section{LFS unemployment estimates}

Figure 6 shows the impact of the population revisions to the LFS working age (16 to 59/64) unemployment levels.

Table A3 also shows the revisions to the unemployment levels for June to August 2007, broken down by age group. The largest revisions were to the period immediately before the reweighting exercise, 0.4 per cent for the working age unemployment estimates.

\section{LFS population revisions by Government Office Region (GOR)}

Figure 7 shows the revisions to the June to August 2007 LFS household population data using the latest population aged 16+ estimates, broken down by region.

The largest upward revision for June to August 2007 was in Yorkshire and The Humber, 65,000. The largest downward revision was seen in London, 106,000. Overall, the estimates for seven regions were revised upwards and five were revised downwards. Table A4 details the changes in the economic activity status of each GOR for June to August 2007 as a result of the latest population estimates. The percentage change between the new and previously used $16+$ population estimates does vary between regions: for Yorkshire and The Humber it peaks at +1.6 per cent in June to August 2007 and for London it reaches -1.7 per cent over the same period. 


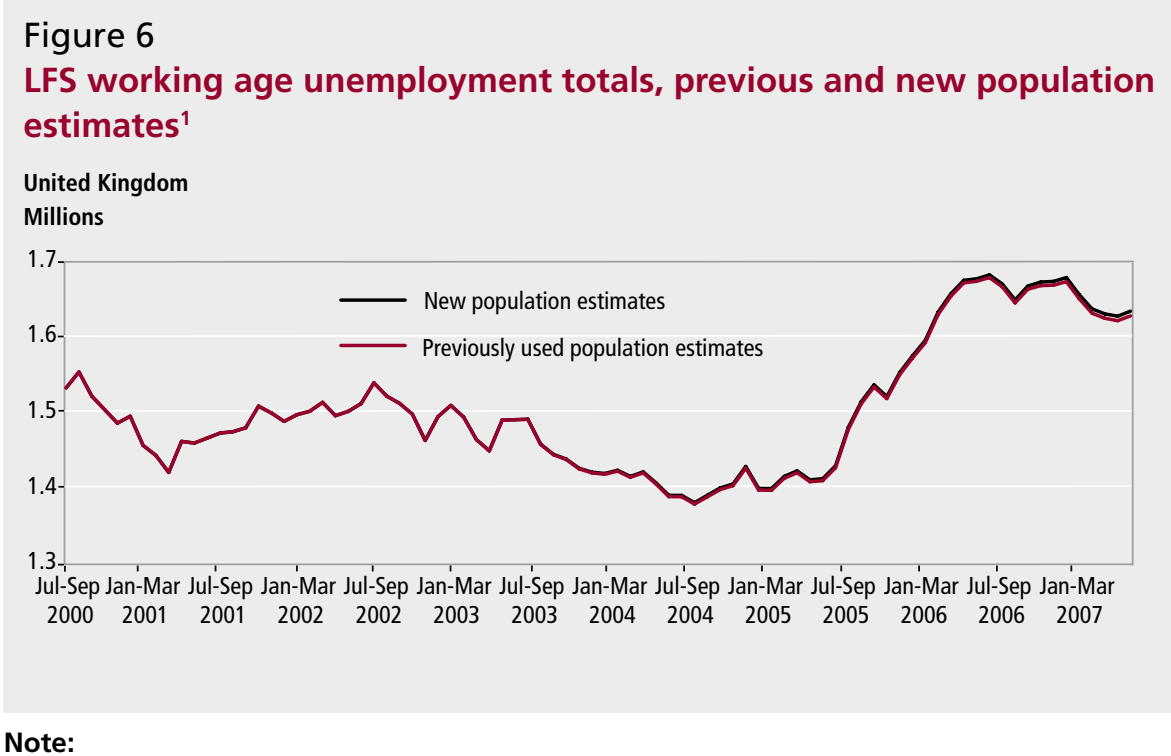

1 Rolling three-month periods, July to September 2000 to June to August 2007.

\section{Figure 7}

LFS aged 16+ population data revisions to levels: by GOR, June to August $2007^{1}$

Thousands

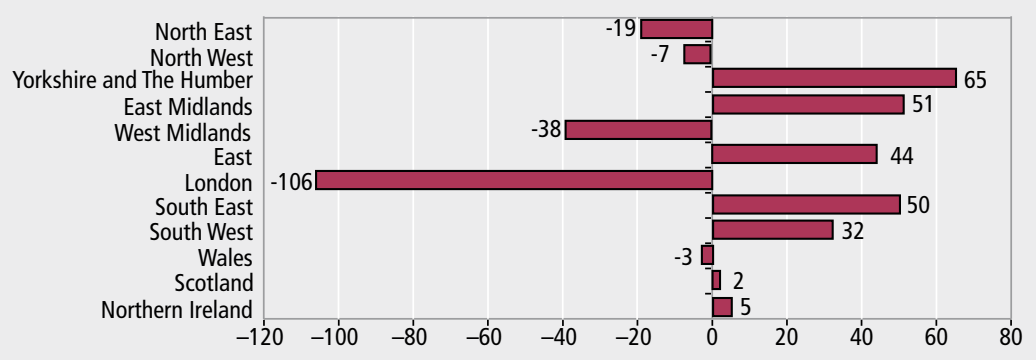

\section{Note:}

1 Rolling three-month period.

\section{APPENDIX}

Table A1

New and previous population aged $16+$ and working age estimates

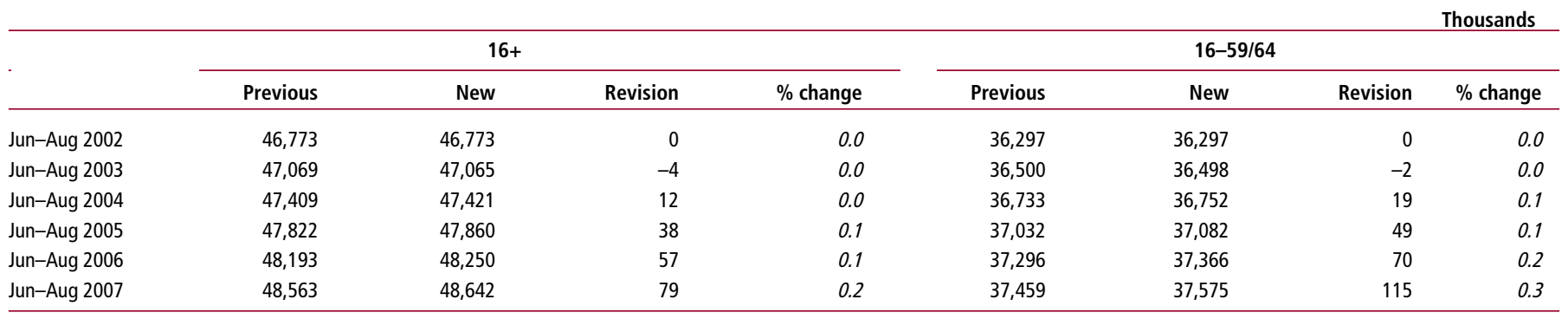

Source: Office for National Statistics

\section{Notes}

1 A more detailed article and information about interim reweighting and inconsistencies between micro- and macro-level data can be found in Labour Market Trends April 2004 at www.statistics.gov.uk/downloads/theme_ labour/lmt_apr04.pdf

2 See www.statistics.gov.uk/statbase/ product.asp?vlnk=1537

\section{CONTACT}

(凶)elmr@ons.gsi.gov.uk 
Table A2

New and previous population estimates: by age band

Thousands

\begin{tabular}{|c|c|c|c|c|c|c|c|c|}
\hline & & & & & & & & Tinusana \\
\hline & & $16-$ & & & & 18-24 & & \\
\hline & Previous & New & Revision & $\%$ change & Previous & New & Revision & $\%$ change \\
\hline Jun-Aug 2002 & 1,514 & 1,512 & -1 & -0.1 & 4,997 & 4,996 & 0 & 0.0 \\
\hline Jun-Aug 2003 & 1,528 & 1,526 & -2 & -0.1 & 5,131 & 5,131 & 0 & 0.0 \\
\hline Jun-Aug 2004 & 1,563 & 1,560 & -2 & -0.2 & 5,248 & 5,268 & 20 & 0.4 \\
\hline Jun-Aug 2005 & 1,578 & 1,573 & -5 & -0.3 & 5,371 & 5,393 & 21 & 0.4 \\
\hline Jun-Aug 2006 & 1,577 & 1,569 & -8 & -0.5 & 5,496 & 5,515 & 19 & 0.3 \\
\hline Jun-Aug 2007 & 1,591 & 1,587 & -3 & -0.2 & 5,591 & 5,633 & 43 & 0.8 \\
\hline & & 25 & & & & $35-49$ & & \\
\hline & Previous & New & Revision & $\%$ change & Previous & New & Revision & $\%$ change \\
\hline Jun-Aug 2002 & 8,175 & 8,183 & 9 & 0.1 & 12,734 & 12,728 & -5 & 0.0 \\
\hline Jun-Aug 2003 & 7,991 & 8,005 & 14 & 0.2 & 12,907 & 12,902 & -5 & 0.0 \\
\hline Jun-Aug 2004 & 7,859 & 7,876 & 17 & 0.2 & 13,063 & 13,057 & -7 & -0.1 \\
\hline Jun-Aug 2005 & 7,818 & 7,857 & 39 & 0.5 & 13,215 & 13,211 & -3 & 0.0 \\
\hline Jun-Aug 2006 & 7,772 & 7,818 & 46 & 0.6 & 13,337 & 13,338 & 1 & 0.0 \\
\hline Jun-Aug 2007 & 7,730 & 7,795 & 65 & 0.8 & 13,420 & 13,424 & 4 & 0.0 \\
\hline & & $50-5$ & & & & $0 / 65+$ & & \\
\hline & Previous & New & Revision & $\%$ change & Previous & New & Revision & $\%$ change \\
\hline Jun-Aug 2002 & 8,878 & 8,877 & -2 & 0.0 & 10,476 & 10,476 & 0 & 0.0 \\
\hline Jun-Aug 2003 & 8,943 & 8,934 & -8 & -0.1 & 10,569 & 10,567 & -2 & 0.0 \\
\hline Jun-Aug 2004 & 9,000 & 8,991 & -9 & -0.1 & 10,676 & 10,669 & -7 & -0.1 \\
\hline Jun-Aug 2005 & 9,051 & 9,048 & -3 & 0.0 & 10,790 & 10,778 & -12 & -0.1 \\
\hline Jun-Aug 2006 & 9,114 & 9,127 & 13 & 0.1 & 10,896 & 10,884 & -13 & -0.1 \\
\hline Jun-Aug 2007 & 9,128 & 9,135 & 8 & 0.1 & 11,104 & 11,068 & -37 & -0.3 \\
\hline
\end{tabular}

Source: Office for National Statistics

Table A3

Changes as a result of the latest population estimates: by age group and economic activity status, June to August 2007

\begin{tabular}{|c|c|c|c|c|}
\hline & & & & Thousands \\
\hline & tive & In employment & Unemployment & Economically inactive \\
\hline $16-17$ & -2 & -1 & 0 & -2 \\
\hline $18-24$ & 31 & 27 & 4 & 11 \\
\hline $25-34$ & 57 & 54 & 3 & 8 \\
\hline $35-49$ & 3 & 3 & 0 & 1 \\
\hline $50-59 / 64$ & 5 & 5 & 0 & 2 \\
\hline 60/65+ & -4 & -4 & 0 & -32 \\
\hline
\end{tabular}

Source: Office for National Statistics

Table A4

Changes as a result of the latest aged $16+$ population estimates: by economic activity status and Government Office Region, June to August 2007

\begin{tabular}{lrrrr}
\hline $\begin{array}{l}\text { Government Office } \\
\text { Region }\end{array}$ & $\begin{array}{r}\text { Economically } \\
\text { active }\end{array}$ & In employment & Tnemployed & $\begin{array}{r}\text { Economically } \\
\text { inactive }\end{array}$ \\
\hline North East & -15 & -15 & -1 & -4 \\
North West & -7 & -7 & 0 & 0 \\
Yorkshire and The Humber & 47 & 43 & 4 & 18 \\
East Midlands & 36 & 33 & 3 & 15 \\
West Midlands & -29 & -27 & -2 & -10 \\
East & 27 & 25 & 2 & 17 \\
& & & & -8 \\
London & -74 & -66 & 1 & 21 \\
South East & 29 & 28 & 1 & 10 \\
South West & 22 & 21 & 0 & 0 \\
Wales & -3 & -3 & 1 & -5 \\
Scotland & 7 & 6 & 0 & 0 \\
Northern Ireland & 5 & 5 & & \\
\hline
\end{tabular}

Source: Office for National Statistics 